\title{
Do biologic therapies reduce aortic inflammation in rheumatoid arthritis patients?
}

D. A. M. Thuy Trang 1,2,3, Koichi Okamura ${ }^{1 *} \mathbb{D}$, Takahito Suto ${ }^{1}$, Hideo Sakane', Yukio Yonemoto', Takahito Nakajima ${ }^{2,4}$, Yoshito Tsushima ${ }^{2,5}$ and Hirotaka Chikuda ${ }^{1}$

\begin{abstract}
Objectives: Rheumatoid arthritis (RA) patients have an increased risk of cardiovascular disease (CVD). In the present study, we evaluated the inflammatory activity of the ascending aorta in RA patients who received biological treatment.

Methods: We assessed the aortic wall inflammation of RA patients using ${ }^{18} \mathrm{~F}$-fluorodeoxyglucose (FDG) positron emission tomography/computed tomography before and after 6 months of biologic therapies. We also compared the inflammatory activity at the aortic wall in RA patients with remission or low disease activity (RLDA) and those with moderate or high disease activity (MHDA). The aortic uptake was measured by the standardized uptake value (SUV) and the target-to-background ratio (TBR).

Results: A total of 64 patients were included in the analysis (mean age, $58.4 \pm 13.8$ years old; female, 77\%). The Disease Activity Score for 28 joints (DAS28) erythrocyte sedimentation rate (ESR) had significantly decreased after 6 months: from $5.0 \pm 1.2$ to $3.3 \pm 1.2(p<0.001)$. The FDG uptake in the ascending aorta changed from baseline to 6 months, showing a maximum SUV (SUV $\max _{\text {ax }}$ of $1.83 \pm 0.34$ to $1.90 \pm 0.34(p=0.059)$ and TBR of $1.71 \pm 0.23$ to 1.75 $\pm 0.24(p=0.222)$. The SUV $\max$ and TBR after 6 months were significantly higher in the RLDA group than in the MHDA group ( $2.05 \pm 0.32$ vs. $1.79 \pm 0.33(p=0.002)$ and $1.89 \pm 0.33$ vs. $1.65 \pm 0.20$ ( $p=0.001)$, respectively). The percentage of monocytes also significantly increased from baseline to 6 months: from $5.9 \pm 1.6$ to $6.9 \pm 2.6$ ( $p=$ 0.032).

Conclusion: The inflammation activity at the ascending aorta in RA patients did not change significantly after 6 months of biological treatment. RA patients with a low disease activity or in clinical remission after 6 months of biological treatment still had an increased inflammatory activity at the aortic wall.
\end{abstract}

Keywords: Aortic inflammation, FDG PET/CT, Biologic therapy, Rheumatoid arthritis

\footnotetext{
*Correspondence: kokamura@gunma-u.ac.jp

${ }^{1}$ Department of Orthopaedic Surgery, Gunma University Graduate School of Medicine, Showamachi 3-39-15, Maebashi, Gunma 371-8511, Japan

Full list of author information is available at the end of the article
}

(c) The Author(s). 2021 Open Access This article is licensed under a Creative Commons Attribution 4.0 International License, which permits use, sharing, adaptation, distribution and reproduction in any medium or format, as long as you give appropriate credit to the original author(s) and the source, provide a link to the Creative Commons licence, and indicate if changes were made. The images or other third party material in this article are included in the article's Creative Commons licence, unless indicated otherwise in a credit line to the material. If material is not included in the article's Creative Commons licence and your intended use is not permitted by statutory regulation or exceeds the permitted use, you will need to obtain permission directly from the copyright holder. To view a copy of this licence, visit http://creativecommons.org/licenses/by/4.0/ The Creative Commons Public Domain Dedication waiver (http://creativecommons.org/publicdomain/zero/1.0/) applies to the data made available in this article, unless otherwise stated in a credit line to the data. 


\section{Background}

Rheumatoid arthritis (RA) increases the risk of cardiovascular disease (CVD) [1-3]. An accelerated progression of atherosclerosis leads to an increased mortality in RA patients [4-10]. Because both an inflamed synovial membrane and atherosclerotic plaque share important common pathological processes, chronic systemic inflammation might accelerate the development of atherosclerosis in RA patients [10]. Previous studies have demonstrated that atherosclerosis is more prevalent in the RA population than in healthy individuals [4-9].

${ }^{18}$ F-fluorodeoxyglucose (FDG) positron emission tomography (PET)/computed tomography (CT) can be used to evaluate the joints in RA patients [11-16]. In addition, FDG PET/CT has also been widely used to evaluate atherosclerosis, since the ${ }^{18}$ F-FDG uptake reflects the glucose metabolism of macrophages in atherosclerotic plaque [17-21]. However, while FDG PET/CT is a highly reproducible method of evaluating arterial inflammation, there have been few reports regarding its utility in assessing aortic inflammation in RA patients.

In the present study, we assessed the ascending aortic wall inflammation in RA patients who received biologic therapies using ${ }^{18}$ F-FDG PET/CT. We also compared the inflammatory activity at the aortic wall in RA patients in remission or with a low disease activity (RLDA) and those with moderate or high disease activity (MHDA) after biologic treatment.

\section{Materials and methods}

\section{Study population}

Sixty-four RA patients who underwent whole-body ${ }^{18} \mathrm{~F}$ FDG PET/CT at baseline and 6 months after the initiation of biologic therapies at Gunma University Hospital were enrolled in this study. All patients were diagnosed with RA according to the American College of Rheumatology criteria revised in 1987 and had a history of inadequate clinical response to previous treatments with nonbiological disease-modifying antirheumatic drugs (DMARDs), such as methotrexate (MTX). Therefore, these patients had been recommended for treatment with biologics.

The study protocol was approved by the Institutional Review Board of Gunma University Hospital. Written, informed consent was obtained from each patient before they participated in the study.

\section{Imaging acquisition}

Whole-body ${ }^{18}$ F-FDG PET/CT was performed using a PET/CT scanner (Biograph 16; Siemens Medical Solutions Inc., Malvern, PA, USA) before and 6 months after the initiation of biologic therapies. In brief, ${ }^{18}$ F-FDG $(5$ $\mathrm{MBq} / \mathrm{kg}$ ) was injected intravenously after at least $6 \mathrm{~h}$ of fasting. Patients were imaged approximately $60 \mathrm{~min}$ after
FDG injection in the supine position. A non-contrastenhanced CT scan (140 kV, 120-240 mAs) for attenuation correction and anatomic co-registration was obtained before PET imaging. PET imaging was performed in the 3-dimensional mode with 3 min per bed position and slice thickness of $3.27 \mathrm{~mm}$. The PET images were reconstructed using an ordered-subsets expectationmaximization algorithm into $128 \times 128$ matrices as previously described $[11,13]$.

\section{Imaging analyses}

Image analyses were performed using the syngo.via software program (Siemens Healthcare, Erlangen, Germany). An independent radiologist blinded to the clinical data analyzed all of the PET/CT images. According to the recommendation of the Cardiovascular Committee of the European Association of Nuclear Medicine (EANM) [22], we used the maximum standardized uptake value $\left(\mathrm{SUV}_{\text {max }}\right)$ and the target-to-background ratio (TBR) as parameters for the FDG uptake in the ascending aorta. The $\mathrm{SUV}_{\max }$ and TBR correlate with histological markers of inflammation and have been used in several studies to measure the FDG uptake in the arterial wall $[17,18,23,24]$.

Ascending aorta inflammation was quantified within each region of interest ( $\mathrm{ROI}$ ), containing the arterial wall and the lumen, along the length of the ascending aorta. The ROIs were manually drawn every $5 \mathrm{~mm}$ on axial images, starting $1 \mathrm{~cm}$ above the origin of the left main coronary artery and ending at the merging point with the aortic arch. The SUV is determined as the radioactivity concentration $(\mathrm{kBq} / \mathrm{ml})$ within an $\mathrm{ROI}$ divided by the decay-corrected amount of injected dose per patient's weight $(\mathrm{kBq} / \mathrm{g})$. The average of the $\mathrm{SUV}_{\max }$ (mean SUVmax) for all ROIs of the entire ascending aorta was then calculated. Subsequently, the TBR was obtained as the mean $\mathrm{SUV}_{\text {max }}$ divided by the background $\mathrm{SUV}_{\max }$ in the superior vena cava to correct for the blood activity.

\section{Clinical and laboratory evaluations}

RA disease activity was assessed using the Disease Activity Score for 28 joints (DAS28) based on the ESR at baseline and 6 months after the initiation of biologic therapies. We also measured the white blood cell (WBC) count, serum levels of erythrocyte sedimentation rate (ESR), C-reactive protein (CRP), matrix metalloproteinase-3 (MMP-3), anti-cyclic citrullinated peptide antibodies (ACPA), and rheumatoid factor antibodies (RF).

The patients were divided into 2 groups according to the DAS28-ESR at 6 months: RLDA in those with a DAS28-ESR $<3.2$ and MHDA in those with a DAS28ESR $\geq 3.2$. The clinical parameters and FDG uptake for 
Table 1 The demographic characteristics and medication use of patients at baseline

\begin{tabular}{ll}
\hline Clinical characteristics & Values \\
\hline Age (years) & $58.4 \pm 13.8$ \\
Female/male & $49 / 15$ \\
Disease duration (years) & $13.1 \pm 11.8$ \\
BMI & $21.8 \pm 4.0$ \\
Smoking, $n$ (\%) & $8(12.7)$ \\
Hypertension, $n$ (\%) & $23(36.5)$ \\
Diabetes, $n$ (\%) & $6(9.7)$ \\
Total cholesterol (mg/dL) & $197.4 \pm 39.3$ \\
LDL (mg/dL) & $114.9 \pm 37.5$ \\
HDL (mg/dL) & $59.6 \pm 15.0$ \\
Triglycerides (mg/dL) & $108.2 \pm 46.0$ \\
PSL use, $n$ (\%) & $31(48.4)$ \\
PSL dose (mg/day) & $2.0 \pm 2.3$ \\
MTX use, $n$ (\%) & $45(70.3)$ \\
MTX dose (mg/week) & $5.7 \pm 3.5$ \\
Biologics (IFX/ETN/ADA/GLM/TCZ/ABT) & $18 / 14 / 16 / 2 / 13 / 1$ \\
\hline The data are expressed as the mean \pm standard deviation &
\end{tabular}

The data are expressed as the mean \pm standard deviation $B M I$ body mass index; $L D L$ low-density lipoprotein cholesterol; $H D L$ highdensity lipoprotein cholesterol; PSL prednisolone; MTX methotrexate; IFX infliximab; ETN etanercept; $A D A$ adalimumab; GLM golimumab; TCZ tocilizumab; $A B T$ abatacept the ascending aorta at baseline were compared between these two groups.

\section{Statistical analyses}

Data analyses were performed using the IBM SPSS Statistics 25 software program (IBM Corp., Armonk, NY, USA). Data were expressed as the mean \pm standard deviation for parametric variables, as the median and interquartile range for nonparametric variables, and as numbers and percentages for categorical variables. For the comparison of continuous data between two clinical response groups, an unpaired Student's $t$-test was used. For the comparison of continuous data before and after treatment, paired Student's $t$-test or Wilcoxon's signedrank test was used. For the comparison of categorical data, the chi-square test or Fisher's exact test was used. A value of $p<0.05$ was considered statistically significant.

\section{Results}

A total of 64 patients were included in the analysis (mean age, $58.4 \pm 13.8$ years old; females, $77 \%$ ) (Table 1). The mean disease duration was $13.1 \pm 11.8$ years. A total of $70 \%$ of the patients received MTX, and $48 \%$ received prednisolone (PSL). Figure 1 shows the ${ }^{18}$ F-FDG PET/
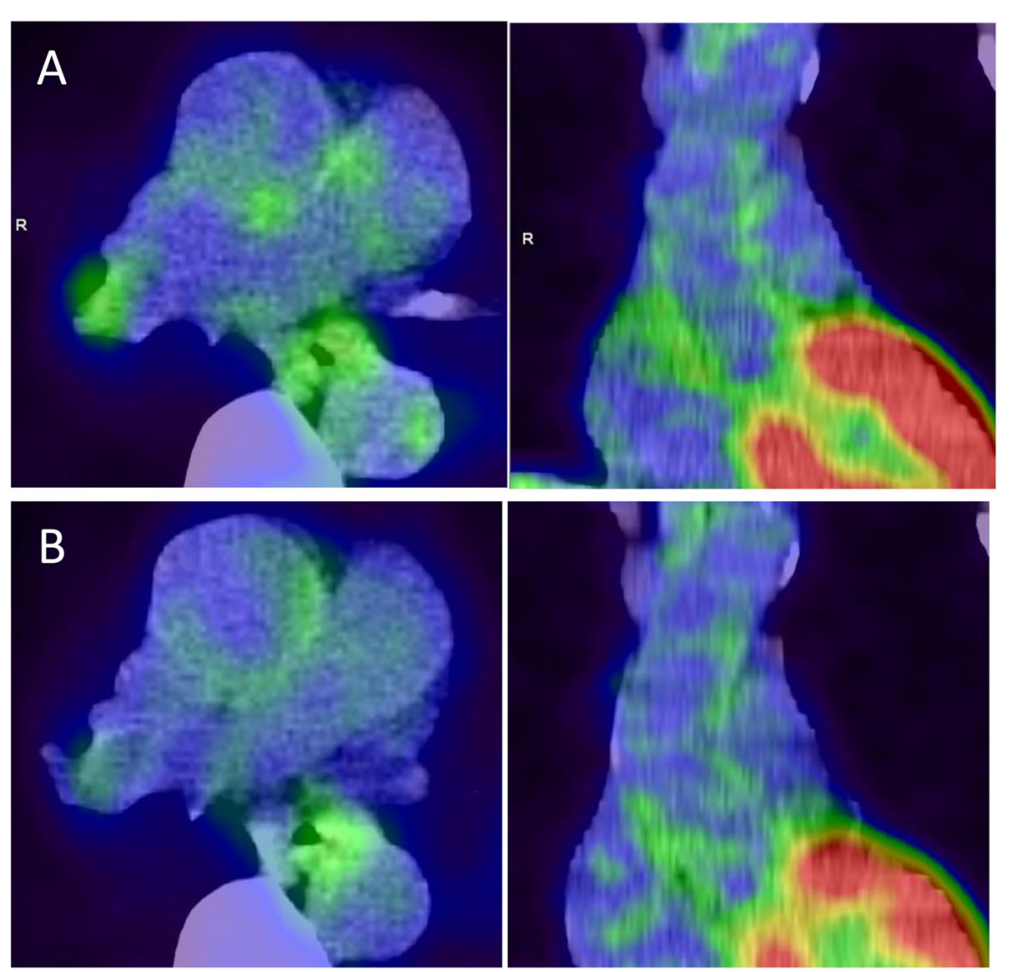

Fig. 1 Typical ${ }^{18}$ F-FDG PET/CT images of the ascending aorta wall uptake at baseline and after 6 months of biologic therapy. Axial and coronal images of ascending aorta from a 65-year-old female patient who underwent treatment with infliximab. A At baseline, the mean SUV $V_{\text {max }}$ was 1.64, and the TBR was 1.63. B At 6 months, the mean SUV $\max$ was 1.56, and the TBR was 1.44. SUV max, maximum standardized uptake value; TBR, target-to-background ratio 
CT findings for a case at baseline and 6 months after the initiation of biologic therapy. The mean FDG uptake values for the ascending aorta and the clinical parameters at baseline and 6 months after the initiation of biologic treatments are shown in Table 2. Although all clinical parameters except for the ACPA were significantly decreased at 6 months compared with the baseline, the mean $\mathrm{SUV}_{\max }$ and TBR were not significantly changed after 6 months (Table 2).

We compared the FDG uptake at the ascending aorta between the two groups (RLDA group vs. MHDA group) at baseline and after 6 months of treatment. Figure 2 shows the increases in the mean $\mathrm{SUV}_{\max }$ and TBR values for the ascending aorta at 6 months after the initiation of treatment, especially in the RLDA group. The mean $\mathrm{SUV}_{\max }$ value at 6 months was significantly higher in the RLDA group than in the MHDA group $(2.05 \pm 0.32$ vs. $1.79 \pm 0.33 ; p=0.002)$. The TBR value at baseline was significantly higher in the RLDA group than in the MHDA group $(1.79 \pm 0.26$ vs. 1.65 $\pm 0.19 ; p=0.018)$. After 6 months, the TBR value was also significantly higher in the RLDA group than

Table 2 Changes in FDG parameters and clinical parameters after treatment

\begin{tabular}{|c|c|c|c|}
\hline Parameters & Baseline & After 6 months & $p$ value \\
\hline \multicolumn{4}{|l|}{ FDG parameters } \\
\hline Mean SUV $\max$ & $1.83 \pm 0.34$ & $1.90 \pm 0.34$ & 0.059 \\
\hline TBR & $1.71 \pm 0.23$ & $1.75 \pm 0.29$ & 0.222 \\
\hline \multicolumn{4}{|l|}{ Clinical parameters } \\
\hline $\operatorname{ESR}(\mathrm{mm} / \mathrm{h})$ & $62.3 \pm 32.2$ & $36.5 \pm 28.6$ & $<0.001$ \\
\hline $\operatorname{CRP}(\mathrm{mg} / \mathrm{dL})^{\mathrm{a}}$ & $1.3(0.4-3.0)$ & $0.1(0.0-0.6)$ & $<0.001$ \\
\hline MMP-3 (ng/mL) & $153.6(70.5-412.6)$ & $65.2(39.3-133.4)$ & $<0.001$ \\
\hline 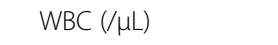 & $6537.5 \pm 2239.2$ & $5609.4 \pm 1992.5$ & $<0.001$ \\
\hline$\%$ neutrophils & $68.7 \pm 9.2$ & $57.9 \pm 12.7$ & $<0.001$ \\
\hline$\%$ eosinophils & $2.3 \pm 2.3$ & $3.0 \pm 2.6$ & 0.004 \\
\hline$\%$ basophils & $0.4 \pm 0.2$ & $0.5 \pm 0.3$ & $<0.001$ \\
\hline$\%$ monocytes & $5.3 \pm 1.8$ & $6.3 \pm 2.2$ & 0.003 \\
\hline \% lymphocytes & $22.2 \pm 7.5$ & $31.3 \pm 11.6$ & $<0.001$ \\
\hline ACPA $(U / m L)^{a}$ & $87.4(12.1-100.0)$ & $55.8(8.0-100.0)$ & 0.276 \\
\hline ACPA positive, $n(\%)$ & $34(53.1)$ & $29(45.3)$ & $<0.001$ \\
\hline $\mathrm{RF}(\mathrm{U} / \mathrm{mL})^{\mathrm{a}}$ & $49(13-137)$ & $27(10-79)$ & $<0.001$ \\
\hline RF positive, $n(\%)$ & $34(53.1)$ & $25(39.1)$ & $<0.001$ \\
\hline DAS28-ESR & $5.0 \pm 1.2$ & $3.3 \pm 1.2$ & $<0.001$ \\
\hline
\end{tabular}

The data are expressed as the mean \pm standard deviation, with the exception of skewed variables $\left({ }^{\mathrm{a}}\right)$, which are represented as medians (interquartile range) SUV $_{\text {max }}$ maximum standardized uptake value; TBR tissue-to-background ratio; $E S R$ erythrocyte sedimentation rate; $C R P$ C-reactive protein; $W B C$ white blood cell count; MMP-3 matrix metalloproteinase-3; ACPA anti-cyclic citrullinated peptide antibody; RF rheumatoid factor; DAS28 Disease Activity Score in 28 joints

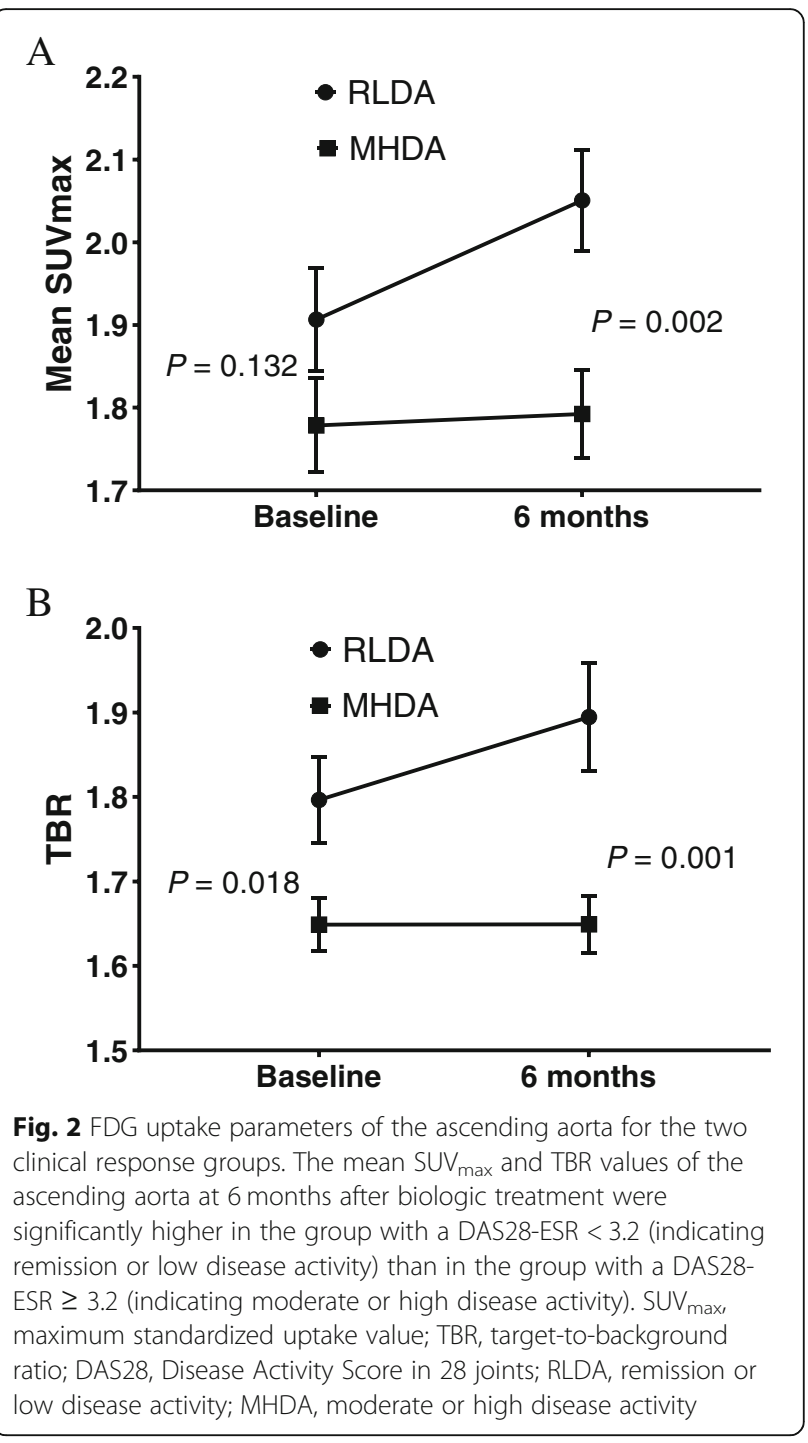

in the MHDA group $(1.89 \pm 0.33$ vs. $1.65 \pm 0.20 ; p=$ 0.001 ).

At baseline, the WBC count and percentage of monocytes were significantly higher in the RLDA group than in the MHDA group ( $p=0.005$ and $p=0.035$ ) (Table 3). Regarding the WBC subtypes at 6 months, there were significantly lower percentages of neutrophils $(p<0.001)$ and significantly higher percentages of lymphocytes $(p<$ 0.001 ) in the RLDA group than in the MHDA group (Table 4). The percentage of monocytes significantly increased from baseline to 6 months $(5.9 \pm 1.6$ to $6.9 \pm 2.6$; $p=0.032$ ).

We compared the FDG uptake and clinical parameters between the groups with and without anti-tumor necrosis factor (TNF) drug treatment, but there were no significant differences between these two groups (data not shown). 
Table 3 The comparison of clinical parameters at baseline

\begin{tabular}{|c|c|c|c|}
\hline & $\operatorname{RLDA}(n=27)$ & MHDA $(n=37)$ & $p$ value \\
\hline Age (years) & $56.3 \pm 15.7$ & $59.9 \pm 12.1$ & 0.334 \\
\hline Female/male & $18 / 9$ & $31 / 6$ & 0.110 \\
\hline Disease duration (years) & $10.3 \pm 8.3$ & $15.1 \pm 13.6$ & 0.082 \\
\hline PSL dose (mg/day) & $2.2 \pm 2.5$ & $1.8 \pm 2.1$ & 0.483 \\
\hline MTX dose (mg/week) & $5.2 \pm 3.4$ & $6.1 \pm 3.6$ & 0.321 \\
\hline ESR $(\mathrm{mm} / \mathrm{h})$ & $53.1 \pm 33.9$ & $68.9 \pm 29.5$ & 0.056 \\
\hline $\operatorname{CRP}(\mathrm{mg} / \mathrm{dL})^{\mathrm{a}}$ & $1.7(0.4-3.1)$ & $1.3(0.6-2.9)$ & 0.807 \\
\hline WBC $(/ \mu \mathrm{L})$ & $7429.6 \pm 2078.1$ & $5886.5 \pm 2150.2$ & 0.005 \\
\hline$\%$ neutrophils & $68.3 \pm 9.2$ & $69.0 \pm 9.3$ & 0.775 \\
\hline$\%$ eosinophils & $2.0 \pm 1.1$ & $2.6 \pm 2.8$ & 0.418 \\
\hline$\%$ basophils & $0.4 \pm 0.2$ & $0.4 \pm 0.2$ & 0.699 \\
\hline$\%$ monocytes & $5.9 \pm 1.6$ & $4.9 \pm 1.9$ & 0.035 \\
\hline \% lymphocytes & $22.4 \pm 7.9$ & $22.0 \pm 7.3$ & 0.857 \\
\hline MMP-3 $(\mathrm{ng} / \mathrm{mL})^{\mathrm{a}}$ & $158.0(95.0-399.3)$ & $134.5(69.1-500.0)$ & 0.579 \\
\hline $\mathrm{ACPA}(\mathrm{U} / \mathrm{mL})^{\mathrm{a}}$ & $61.4(10.7-100.0)$ & $99.1(15.1-100.0)$ & 0.393 \\
\hline $\mathrm{ACPA} \geq 60 \mathrm{U} / \mathrm{mL}, n(\%)$ & $13(50.0)$ & $21(58.3)$ & 0.515 \\
\hline $\mathrm{RF}(\mathrm{U} / \mathrm{mL})^{\mathrm{a}}$ & $33(10-100)$ & $61.5(23.8-211.8)$ & 0.082 \\
\hline $\mathrm{RF} \geq 40 \mathrm{U} / \mathrm{mL}, n(\%)$ & $12(48.0)$ & $22(64.7)$ & 0.199 \\
\hline DAS28-ESR & $4.5 \pm 1.4$ & $5.3 \pm 1.0$ & 0.008 \\
\hline
\end{tabular}

The data are expressed as the mean \pm standard deviation, with the exception of skewed variables $\left({ }^{\mathrm{a}}\right)$, which are represented as medians (interquartile range) $R L D A$ remission and low disease activity; $M H D A$ moderate and high disease activity; PSL prednisolone; MTX methotrexate; ESR erythrocyte sedimentation rate; $C R P$ C-reactive protein; WBC white blood cell count; MMP-3 matrix metalloproteinase-3; ACPA anti-cyclic citrullinated peptide antibody; $R F$ rheumatoid factor; DAS28 Disease Activity Score in 28 joints

\section{Discussion}

In the present study, we found that the inflammation activity of the ascending aorta in RA patients did not significantly change after 6 months of biologic treatment. RA patients with RLDA after 6 months had a significantly higher FDG uptake at the aortic wall than those with MDLA.

Biological agents showed beneficial effects on reducing RA symptoms and disease activity by suppressing

Table 4 Counts for WBC subtypes at 6 months in the two groups

\begin{tabular}{llll}
\hline & RLDA $(\boldsymbol{n}=\mathbf{2 7})$ & MHDA $(\boldsymbol{n}=\mathbf{3 7})$ & $\boldsymbol{p}$ value \\
\hline WBC $(/ \mu \mathrm{L})$ & $5807.4 \pm 1994.2$ & $5465.0 \pm 2006.1$ & 0.501 \\
\% neutrophils & $51.3 \pm 12.0$ & $62.8 \pm 11.0$ & $<\mathbf{0 . 0 0 1}$ \\
\% eosinophils & $2.8 \pm 2.0$ & $3.0 \pm 2.9$ & 0.881 \\
\% basophils & $0.6 \pm 0.4$ & $0.4 \pm 0.2$ & 0.114 \\
\% monocytes & $6.9 \pm 2.6$ & $5.8 \pm 1.7$ & 0.065 \\
\% lymphocytes & $37.7 \pm 11.3$ & $26.7 \pm 9.5$ & $<\mathbf{0 . 0 0 1}$ \\
\hline
\end{tabular}

The data are expressed as the mean \pm standard deviation $R L D A$ remission and low disease activity; $M H D A$ moderate and high disease activity; WBC white blood cell inflammation. Since atherosclerosis is a chronic inflammation process, these drugs may be also effective in reducing CVD risk in RA. Previous reports have shown that 8-week anti-TNF- $\alpha$ therapy reduced aortic inflammation in RA patients [25]. However, the FDG uptake of the arterial wall after treatment was still significantly higher in RA patients than in the control group.

In our study, although the disease activity and serum markers of RA patients significantly decreased after 6 months of biologic treatment, the inflammatory activity of the ascending aorta still existed. This result indicated that the cardio-protective effects of biologic therapy might not apply to all RA patients at six months.

A cross-sectional study in the USA demonstrated that RA patients who needed anti-TNF therapy to continue their clinical remission had a greater FDG uptake at the ascending aorta than those receiving non-biological DMARDs [26]. In addition to the high disease activity before the biological treatment, our patients had a long disease duration after the onset of RA. These patients' condition might have led to the remnant aortic inflammation after 6 months of biological treatment, even if their joints had a good clinical response to biological drugs. Our results indicated that if we were intending to use biological drugs to achieve a cardio-protective effect, we should ensure RA patients maintain a low disease activity for a long time.

The FDG uptake in the aortic wall was significantly higher in RA patients with RLDA than in those with MHDA at 6 months. This was a controversial result. However, as mentioned above, our follow-up period was only 6 months and thought to be insufficient to reduce systemic inflammation by RA. It is thus possible that a longer treatment period led to the reduced aortic inflammation in the RLDA group.

In addition, a 3-year, prospective, observational study in an Italian cohort clearly showed that the maintenance of remission was associated with a reduced risk of atherosclerosis [27]. Our results showed that while the use of biologic therapies had reduced the clinical symptoms at 6 months, the aortic wall inflammation in these patients persisted despite 6 months of biologic treatment. Therefore, tight control of the RA activity in these patients should be maintained, and their CVD risk should be carefully estimated.

In this study, we also noted an elevation of monocytes at baseline and at 6 months in the RLDA group. An increased activation of circulating monocytes has been reported in patients receiving anti-TNF therapy [26] and the elevations of monocyte subpopulation can be seen in RA patients with coronary artery atherosclerosis and are associated with an increased CVD risk [28, 29]. Furthermore, a previous in vivo imaging study reported that the peripheral blood mononuclear cell accumulation was 
correlated with the arterial wall inflammation assessed on hybrid single-photon emission computed tomography/CT [30]. These previous findings suggest that the increased percentage of monocytes might be involved in arterial wall inflammation in RA patients, even after biologic therapy.

Several limitations associated with the present study warrant mention. First, traditional cardiovascular risk factors could not be fully investigated because of the lack of such information. Second, the selection of biologic agents was left to each physician. Since different drugs have different mechanisms through which they act on RA pathogenesis, treatment bias may exist. Third, since FDG-PET/CT is a nuclear imaging modality, repeated examinations might lead to increased radiation exposure. Finally, this was a short-term study. To determine whether or not biological therapies are useful for reducing aortic inflammation and CVD risk in RA patients, further longterm follow-up research should be conducted.

\section{Conclusions}

We demonstrated that the inflammation activity of the ascending aorta in RA patients was not significantly altered after 6 months of biologic treatment. RA patients with a low disease activity or in clinical remission after 6 months of such treatment still had an increased inflammatory activity at the aortic wall.

\begin{abstract}
Abbreviations
ACPA: Anti-cyclic citrullinated peptide antibody; CRP: C-reactive protein; DAS: Disease activity score; DMARDs: Disease-modifying antirheumatic drugs; CVD: Cardiovascular disease; EANM: European association of nuclear medicine; ESR: Erythrocyte sedimentation rate; FDG-PET/

CT: Fluorodeoxyglucose-positron emission tomography/computed tomography; RLDA: RA patients in remission or with a low disease activity; MHDA: RA patients with moderate or high disease activity; MMP-3: Matrix metalloproteinase 3; MTX: Methotrexate; PSL: Prednisolone; RA: Rheumatoid arthritis; RF: Rheumatoid factor; ROI: Region of interest; SUV: Standardized uptake value; SUVmax: Maximum standardized uptake value; TBR: Target-tobackground ratio; TNF: Tumor necrosis factor; WBC: White blood cell
\end{abstract}

\section{Acknowledgements}

None.

\section{Authors' contributions}

DTT and KO made substantial contributions to the design of the study; acquisition, analysis, and interpretation of the data; and writing of the manuscript. TS and YY participated in the design of the study, acquired the data, helped to draft the manuscript, and contributed to the revising of the manuscript critically. HS and TN participated in acquiring the data and critically contributing to the revising of the manuscript. YT and $\mathrm{HC}$ critically contributed to the revising of the manuscript enhancing its intellectual content and approving the final content of the manuscript. All authors read and approved the final manuscript.

\section{Funding}

There has been no significant financial support for this work that could have influenced its outcome. The authors acknowledge the financial support provided by a UCB Japan Grant (UCBJ Grant) for the English proofreading and article processing charge of the journal.
Availability of data and materials

All data generated or analyzed during this study are included in this published article and its supplementary information file.

\section{Declarations}

Ethics approval and consent to participate

Ethical approval was obtained from the institutional review board of the Gunma University Hospital. Patients provided written informed consent before taking part in this study.

\section{Competing interests}

The authors declare that they have no competing interests.

\section{Author details}

1 Department of Orthopaedic Surgery, Gunma University Graduate School of Medicine, Showamachi 3-39-15, Maebashi, Gunma 371-8511, Japan. ${ }^{2}$ Department of Diagnostic Radiology and Nuclear Medicine, Gunma University Graduate School of Medicine, Showa-machi 3-39-15, Maebashi, Gunma 371-8511, Japan. ${ }^{3}$ Radiology Center, Bach Mai Hospital, Hanoi, Vietnam. ${ }^{4}$ Department of Diagnostic Radiology and Interventional Radiology, Tsukuba University, Tsukuba, Ibaraki, Japan. ${ }^{5}$ Research Program for Diagnostic and Molecular Imaging, Division of Integrated Oncology Research, Gunma University Initiative for Advanced Research (GIAR), Maebashi, Gunma, Japan.

Received: 13 May 2021 Accepted: 14 July 2021

Published online: 03 August 2021

\section{References}

1. Peters MJL, van Halm VP, Voskuyl AE, Smulders YM, Boers M, Lems WF, et al. Does rheumatoid arthritis equal diabetes mellitus as an independent risk factor for cardiovascular disease? A prospective study. Arthritis Care Res. 2009;61(11):1571-9. https://doi.org/10.1002/art.24836

2. del Rincon ID, Williams K, Stern MP, Freeman GL, Escalante A. High incidence of cardiovascular events in a rheumatoid arthritis cohort not explained by traditional cardiac risk factors. Arthritis Rheumatism. 2001; 44(12):2737-45. https://doi.org/10.1002/1529-0131(200112)44:12<2737::AID-A RT460>3.0.CO;2-\#.

3. Crowson CS, Liao KP, Davis JM 3rd, Solomon DH, Matteson EL, Knutson KL, et al. Rheumatoid arthritis and cardiovascular disease. Am Heart J. 2013; 166(4):622-8 e1. https://doi.org/10.1016/j.ahj.2013.07.010.

4. Skeoch S, Cristinacce PLH, Williams H, Pemberton P, Xu D, Sun J, et al. Imaging atherosclerosis in rheumatoid arthritis: evidence for increased prevalence, altered phenotype and a link between systemic and localised plaque inflammation. Sci Rep. 2017;7(1):827. https://doi.org/10.1038/s41598017-00989-w

5. Jonsson SW, Backman C, Johnson O, Karp K, Lundstrom E, Sundqvist KG et al. Increased prevalence of atherosclerosis in patients with medium term rheumatoid arthritis. J Rheumatol. 2001;28(12):2597-602.

6. Gonzalez-Juanatey C, Llorca J, Testa A, Revuelta J, Garcia-Porrua C, GonzalezGay MA. Increased prevalence of severe subclinical atherosclerotic findings in long-term treated rheumatoid arthritis patients without clinically evident atherosclerotic disease. Medicine. 2003;82(6):407-13. https://doi.org/10.1097/ 01.md.0000101572.76273.60.

7. Hannawi S, Haluska B, Marwick TH, Thomas R. Atherosclerotic disease is increased in recent-onset rheumatoid arthritis: a critical role for inflammation. Arthritis Res Ther. 2007;9(6):R116. https://doi.org/10.1186/a r2323.

8. Aubry M-C, Maradit-Kremers H, Reinalda MS, Crowson CS, Edwards WD, Gabriel SE. Differences in atherosclerotic coronary heart disease between subjects with and without rheumatoid arthritis. J Rheumatol. 2007;34(5): 937-42.

9. Semb AG, Rollefstad S, Provan SA, Kvien TK, Stranden E, Olsen IC, et al. Carotid plaque characteristics and disease activity in rheumatoid arthritis. J Rheumatol. 2013;40(4):359-68. https://doi.org/10.3899/jrheum.120621.

10. Skeoch S, Bruce IN. Atherosclerosis in rheumatoid arthritis: is it all about inflammation? Nat Rev Rheumatol. 2015;11(7):390-400. https://doi.org/10.1 038/nrrheum.2015.40.

11. Okamura K, Yonemoto Y, Arisaka Y, Takeuchi K, Kobayashi T, Oriuchi N, et al. The assessment of biologic treatment in patients with rheumatoid arthritis 
using FDG-PET/CT. Rheumatology. 2012;51(8):1484-91. https://doi.org/10.1 093/rheumatology/kes064

12. Okamura K, Yonemoto Y, Okura C, Higuchi T, Tsushima Y, Takagishi K. Evaluation of tocilizumab therapy in patients with rheumatoid arthritis based on FDG-PET/CT. BMC Musculoskelet Disord. 2014;15(1):393. https:// doi.org/10.1186/1471-2474-15-393.

13. Suto T, Okamura K, Yonemoto Y, Okura C, Tsushima Y, Takagishi K. Prediction of large joint destruction in patients with rheumatoid arthritis using 18F-FDG PET/CT and Disease Activity Score. Medicine. 2016;95(7): e2841. https://doi.org/10.1097/MD.0000000000002841.

14. Suto T, Yonemoto Y, Okamura K, Okura C, Kaneko T, Kobayashi T, et al. Predictive factors associated with the progression of large-joint destruction in patients with rheumatoid arthritis after biologic therapy: a post-hoc analysis using FDG-PET/CT and the ARASHI (assessment of rheumatoid arthritis by scoring of large-joint destruction and healing in radiographic imaging) scoring method. Modern Rheumatol. 2017;27(5):820-7. https://doi. org/10.1080/14397595.2016.1266132.

15. Yonemoto Y, Okamura K, Takeuchi K, Kaneko T, Kobayashi T, Okura C, et al. [18F]fluorodeoxyglucose uptake as a predictor of large joint destruction in patients with rheumatoid arthritis. Rheumatol Int. 2016;36(1):109-15. https:// doi.org/10.1007/s00296-015-3331-0.

16. Yonemoto $\mathrm{Y}$, Okamura K, Kobayashi T, Kaneko T, Okura C, Suto T, et al. Predictive factors related to shoulder joint destruction in rheumatoid arthritis patients treated with biologics: a prospective study. Mod Rheumatol. 2017;27(4):587-92. https://doi.org/10.1080/14397595.2016.124 5125 .

17. Rudd JHF, Warburton EA, Fryer TD, Jones HA, Clark JC, Antoun N, et al. Imaging atherosclerotic plaque inflammation with [18F]-fluorodeoxyglucose positron emission tomography. Circulation. 2002;105(23):2708-11. https:// doi.org/10.1161/01.CIR.0000020548.60110.76.

18. Tawakol A, Migrino RQ, Bashian GG, Bedri S, Vermylen D, Cury RC, et al. In Vivo 18F-fluorodeoxyglucose positron emission tomography imaging provides a noninvasive measure of carotid plaque inflammation in patients. J Am Coll Cardiol. 2006;48(9):1818-24. https://doi.org/10.1016/j.jacc.2006.05. 076.

19. Græbe M, Pedersen SF, Borgwardt L, Højgaard L, Sillesen H, Kjær A. Molecular pathology in vulnerable carotid plaques: correlation with [18] fluorodeoxyglucose positron emission tomography (FDG-PET). Eur J Vasc Endovasc Surg. 2009;37(6):714-21. https://doi.org/10.1016/j.ejvs.2008.11.018.

20. Paulmier B, Duet M, Khayat R, Pierquet-Ghazzar N, Laissy J-P, Maunoury C, et al. Arterial wall uptake of fluorodeoxyglucose on PET imaging in stable cancer disease patients indicates higher risk for cardiovascular events. J Nuclear Cardiol. 2008;15(2):209-17. https://doi.org/10.1016/j.nuclcard.2007.1 0.009 .

21. Rominger A, Saam T, Wolpers S, Cyran CC, Schmidt M, Foerster S, et al. 18FFDG PET/CT identifies patients at risk for future vascular events in an otherwise asymptomatic cohort with neoplastic disease. J Nuclear Med. 2009:50(10):1611-20. https://doi.org/10.2967/jnumed.109.065151.

22. Bucerius J, Hyafil F, Verberne HJ, et al. Position paper of the Cardiovascular Committee of the European Association of Nuclear Medicine (EANM) on PET imaging of atherosclerosis. Eur J Nucl Med Mol Imaging. 2016;43(4): 780-92. https://doi.org/10.1007/s00259-015-3259-3.

23. Figueroa AL, Abdelbaky A, Truong QA, Corsini E, MacNabb MH, Lavender $Z R$, et al. Measurement of arterial activity on routine FDG PET/CT images improves prediction of risk of future CV events. JACC Cardiovasc Imaging. 2013;6(12):1250-9. https://doi.org/10.1016/j.jcmg.2013.08.006.

24. Tawakol A, Fayad ZA, Mogg R, Alon A, Klimas MT, Dansky H, et al. Intensification of statin therapy results in a rapid reduction in atherosclerotic inflammation: results of a multicenter fluorodeoxyglucose-positron emission tomography/computed tomography feasibility study. J Am Coll Cardiol. 2013;62(10):909-17. https://doi.org/10.1016/j.jacc.2013.04.066.

25. Maki-Petaja KM, Elkhawad M, Cheriyan J, Joshi FR, Ostor AJ, Hall FC, et al. Anti-tumor necrosis factor-alpha therapy reduces aortic inflammation and stiffness in patients with rheumatoid arthritis. Circulation. 2012;126(21):247380. https://doi.org/10.1161/CIRCULATIONAHA.112.120410.

26. Bernelot Moens SJ, van der Valk FM, Strang AC, Kroon J, Smits LP, Kneepkens EL, et al. Unexpected arterial wall and cellular inflammation in patients with rheumatoid arthritis in remission using biological therapy: a cross-sectional study. Arthritis Res Ther. 2016;18(1):115. https://doi.org/10.11 86/s13075-016-1008-z.
27. Ruscitti P, Cipriani P, Liakouli V, lacono D, Pantano I, Margiotta DPE, et al. Subclinical and clinical atherosclerosis in rheumatoid arthritis: results from the 3-year, multicentre, prospective, observational GIRRCS (Gruppo Italiano di Ricerca in Reumatologia Clinica e Sperimentale) study. Arthritis Res Ther. 2019;21(1):204. https://doi.org/10.1186/s13075-019-1975-y.

28. Winchester R, Giles JT, Nativ S, Downer K, Zhang H-Z, Bag-Ozbek A, et al. Association of elevations of specific $T$ cell and monocyte subpopulations in rheumatoid arthritis with subclinical coronary artery atherosclerosis. Arthritis Rheumatol. 2016;68(1):92-102. https://doi.org/10.1002/art.39419.

29. Ruiz-Limon P, Ortega-Castro R, Barbarroja N, Perez-Sanchez C, Jamin C, Patiño-Trives AM, et al. Molecular characterization of monocyte subsets reveals specific and distinctive molecular signatures associated with cardiovascular disease in rheumatoid arthritis. Front. Immunol. 10:1111. https://doi.org/10.3389/fimmu.2019.01111

30. van der Valk FM, Kroon J, Potters WW, Thurlings RM, Bennink RJ, Verberne $\mathrm{HJ}$, et al. In vivo imaging of enhanced leukocyte accumulation in atherosclerotic lesions in humans. J Am Coll Cardiol. 2014;64(10):1019-29. https://doi.org/10.1016/j.jacc.2014.06.1171.

\section{Publisher's Note}

Springer Nature remains neutral with regard to jurisdictional claims in published maps and institutional affiliations.
Ready to submit your research? Choose BMC and benefit from:

- fast, convenient online submission

- thorough peer review by experienced researchers in your field

- rapid publication on acceptance

- support for research data, including large and complex data types

- gold Open Access which fosters wider collaboration and increased citations

- maximum visibility for your research: over $100 \mathrm{M}$ website views per year

At BMC, research is always in progress.

Learn more biomedcentral.com/submissions 